\title{
Beyond Empathic Media
}

\author{
Ho Manh Tung \\ Ritsumeikan Asia Pacific University
}

Beppu, Oita, Japan

October 21, 2020

In Emotional AI: The rise of empathic media, McStay (2018) explores what will happen when media technologies are increasingly able to read, sense, track, and classify human emotions. One of the pivotal concepts used in the book is 'empathy.' The author analogizes the capacity for empathy of humans with that of machines. Like humans, machines can also have a failure of empathy. Like humans, machines can draw from past observations, which are vaster and more diverse than any human can potentially imagine, to make predictions about the present and future of emotional states. The author argues the implications of machines that have a growing capacity for empathy - the empathic media, must be carefully analyzed and understood if we want to engender a life worth living in the future smart cities.

The book presents one of the fullest accounts of the current state-of-the-art emotional artificial intelligence (AI) systems. The author calls our attention to a plethora of new concepts such as empathic media, empathic cities, algocracy, and psycho-geography, which are arguably very relevant to our modern living yet remain largely esoteric to the public. McStay takes pain to present a balanced account of the potential effects of "machines that feel": while these new media 
technologies contain both the threat of inaccuracy and the threat to our autonomy, they are capable of improve our well-being immensely.

One of the shortcomings of McStay's account of empathic media and emotional AI is that the author does not offer a more comprehensive conceptual and empirical analysis of empathy. McStay focuses on two aspects of (i) empathy as "a social fact," which fosters mutual understanding and awareness among agents in societies, and, (ii) empathy as projection and simulation of feelings — the "feeling-into" (Lipps, 1979) or "feel-forward" sense. While these two aspects largely capture our understanding of empathy in daily life, in order to envision an ethical life living in McStay's empathic cities with empathic media, I believe a more comprehensive analysis of the concept is necessary.

For example, Yale psychologist Paul Bloom (2017a, b) makes a convincing case that empathy — "the feeling of experiencing what we believe others experience," is often not a reliable guide for our moral-decision making. Citing evidence from courthouse and laboratories, Bloom shows that we are more inclined to feel more empathy and become biased toward those who resemble us and those who are more attractive. Empathy can certainly inspire kindnesses, but when we consider someone or a group of people enemy, empathy can facilitate the process of inflicting pain on the enemies. Moreover, empathy has serious limitations in terms of moral reasoning. In a seminal experiment by Paul Slovic (2007), it is shown to increase the most when presented with examples of a single identified suffering individual. But when we are encountered with statistics of a large group of suffering people, empathy diminishes. Slovic terms this phenomenon "psychic numbing."

Thus, to further understand the ethical implications of empathic media and emotional AI, a more comprehensive account of empathy, with its limitations and its remedy, such as that of 
Bloom (2017a), is necessary. Bloom differentiates between "cognitive empathy," "emotional contagion," "affective empathy," and "compassion" as different common senses of "empathy." Cognitive empathy is about understanding others' feelings. Simultaneously, one does not feel it; affective empathy is about feeling the inferred feelings of others; emotional contagion is about feeling the feelings of those within one's immediate environment. Bloom then focuses his argument on affective empathy and compassion. He argues affective empathy often leads to bias and emotional burnout. At the same time, compassion, the feeling of wishing well and caring for others without feeling what they feel, can be a great alternative for motivating our prosocial behavior.

In the context of emotional AI and empathic media, all four types of empathy are important. It appears that although machines are increasingly getting better at classifying and reading our emotions, until we have an account of machine consciousness, the empathy machines show us will be limited to cognitive empathy. However, it must be acknowledged that current machines and algorithms can generate mass instances of emotional contagion by leveraging our digital lives' hyperconnectivity. This clearly has implications for our interactions with the new emergences of marketing, journalism, and political campaign.

McStay coins and uses the term "machinic verisimilitude" to sidestep the issue that the empathy machines are capable of are not authentic but only "the appearance of intimate insight" (2018, p.5). This is to say, and the author acknowledges, machines and humans are not equivalent. But it is still true that machinic verisimilitude alone has already transformed and had serious implications for our lives: we are afforded new abilities to communicate, to gauge emotional reactions of others, and to engage in new aesthetic experiences, as laid out in the book. 
However, McStay's (2018) lack of further investigating other notions of empathy and how machines can implement them feels like a missed opportunity, to say the least. Differentiating the nuances of used terminology not only facilitates the deepest intellectual exploration and the avoidance of unforced errors, but also signifies intellectual rigor, honesty, and humility (Vuong, 2020). For example, one wonders whether empathic media can be programmed in a way that helps us avoid burnout and bias when we experience affective empathy. Or can it be tasked with enhancing our feeling of compassion and altruism? With the capacity to cause mass instances of emotional contagion, how can we deploy empathic media to fight against the wrong kind of moral panic?

These issues are especially important because the current evidence suggests that the smart algorithms being used for news/videos recommendations, product advertisements, courtrooms decisions, etc. seem only to amplify our entrenched biases and social conflicts. The algorithms and their designers seem impervious toward the issue of acculturation (Vuong \& Napier, 2015; Vuong et al., 2020) that lies at the root of our emotionally-conflicted digital lives. Thus, it is only rational to start philosophizing beyond empathic media. Reading McStay's Empathic media, readers are left to wonder about compassionate media.

\section{References}

Bloom, P. (2017a). Against empathy: The case for rational compassion. London, UK: Random House.

Bloom, P. (2017b). Empathy and its discontents. Trends in Cognitive Sciences, 21(1), 24-31. doi:https://doi.org/10.1016/j.tics.2016.11.004

McStay, A. (2018). Emotional AI: The rise of empathic media. London: Sage. 
Slovic, P. (2007). "If I look at the mass, I will never act": Psychic numbing and genocide. Judgment and Decision Making, 2(2), 79-95.

Vuong, Q. H., \& Napier, N. K. (2015). Acculturation and global mindsponge: an emerging market perspective. International Journal of Intercultural Relations, 49, 354-367.

Vuong, Q.-H., Ho, M.-T., Nguyen, H.-K. T., et al. (2020). On how religions could accidentally incite lies and violence: folktales as a cultural transmitter. Palgrave Communications, 6(1), 82.

Vuong, Q. H. (2020). Reform retractions to make them more transparent. Nature, 582(7811), 149. 